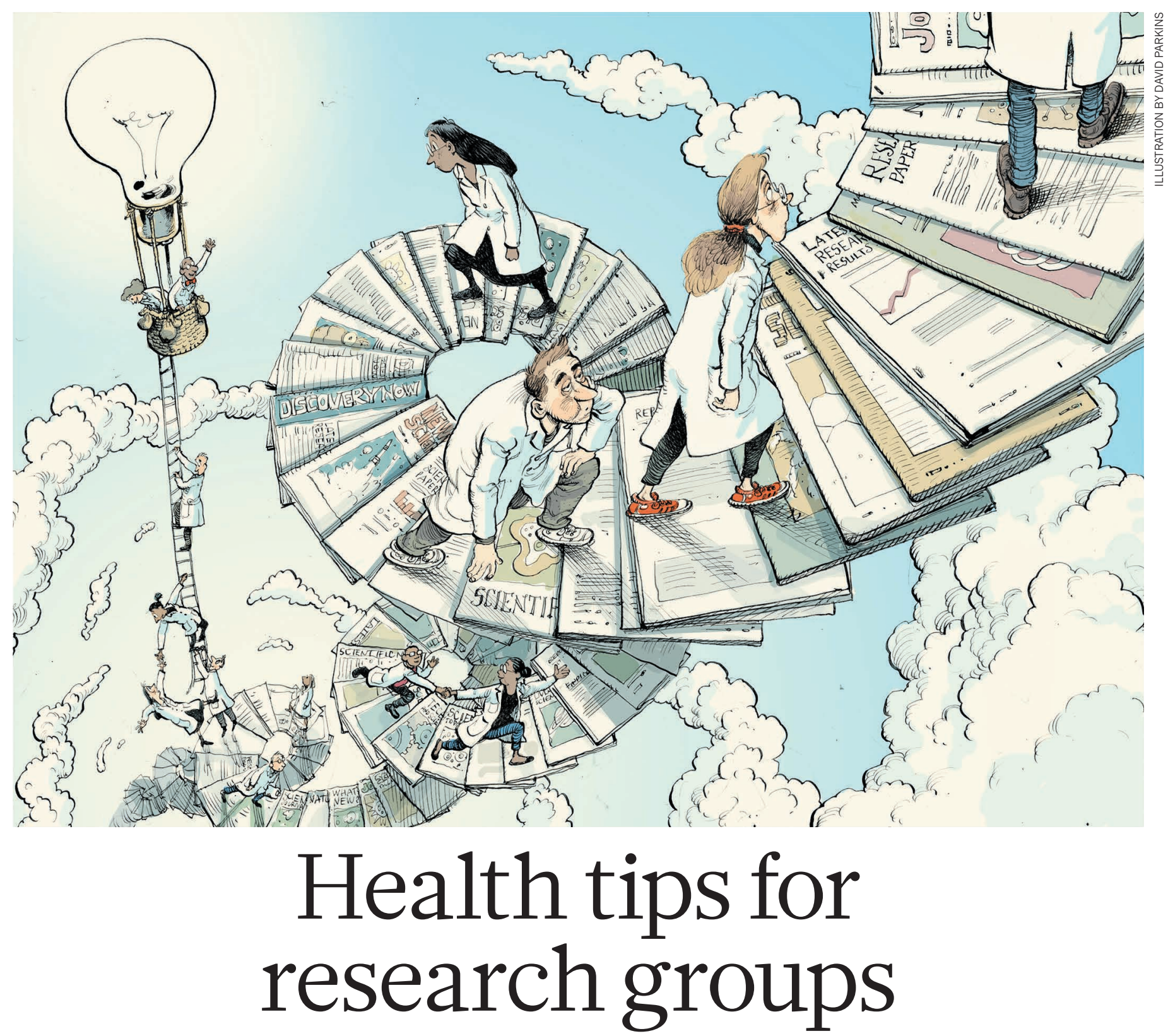

Nature asked scientists to recommend one thing that institutional and laboratory leaders could do to make science more productive, rigorous and happy.

\section{DAVID NORRIS}

\section{Make lab health someone's job}

Director of research, Donders Institute for Brain, Cognition and Behaviour, Radboud University, Nijmegen, the Netherlands.

Just over two years ago, our institute created a new position: sustainable-science officer. The job is to improve the working environment for everyone at our research centre. The effort succeeded.
The impetus grew from an internal colloquium about the future of science that took a surprising direction. More than 100 scientists attended, and both senior and junior researchers opened up about how trapped they felt in the current system of chasing publication credit to secure career prospects. Discussion spilled well over the time allotted. It was like people had finally been given a forum to say what they had previously kept to themselves.

The institute's directors decided to take

\begin{tabular}{r|l|}
\hline & LAB HEALTH \\
$r$ & $\begin{array}{l}\text { A Nature special issue } \\
\text { nature.com/collections/labhealth }\end{array}$ \\
\hline
\end{tabular}

action. I was then chair of the board, and we set out to identify what we could do ourselves, without waiting for action by funders or journals.

I canvassed the institute, e-mailing our 600 researchers an analysis of the discussion and asking for their thoughts. Problems fell into about 20 themes, including a disconnect between $\mathrm{PhD}$ graduation and academic positions, lack of incentives for multidisciplinary collaborations and a reward system that can penalize high-quality science. We formed workgroups around each theme to set tangible goals. Once people realized that the leadership was prepared to act, there was no shortage of volunteers.

Next, we crafted the role of science 
sustainability officer, and hired Claudia Lüttke, a graduate student who had moved into science management. Her job, just over half-time and supported by internal funds, was to hold us accountable to our ideals. She was also someone whom trainees and faculty members could approach to talk through concerns and ideas.

The changes were broad (see go.nature. com/2kt3ka3). The institute, backed by the university, created a data-management programme to share and archive experimental results. We now assess scientific output on the basis of quality and do not have quantity as an explicit criterion. To encourage team science, we allow publications to feature in more than one student's $\mathrm{PhD}$ thesis, provided that joint authors made clear and distinct contributions. We established peer coaching teams of 4-6 researchers, run by volunteer facilitators who receive professional training. We instituted career-development plans for postdocs that give them the time and resources to devote to their own future. Everyone at the institute can access designated contacts outside their lab group to discuss good scientific practice informally (generally someone who is also an assistant or associate professor).

Even more importantly, we established a culture of openly discussing community issues across lab groups and among junior and senior researchers. Topics such as burnout, data-sharing dilemmas and $\mathrm{PhD}$ pressures have featured alongside neuroscience topics at weekly and monthly all-institute seminars. At meetings set up for trainees, principal investigators (PIs) talk about issues such as how they maintain work-life balance or make decisions about hiring postdocs. Our graduate students have been surprised that qualities such as enthusiasm and insight during job interviews could outrank the prominence and quantity of papers.

Unless specific people are charged by the institution with specific duties, sustainable science will not sustain itself. Lüttke has moved on to become a policy officer at another university, and her former role has been incorporated explicitly into a new senior position.

I believe that our scientific output is now as good or better than it was under the conventional system. It certainly generates less stress and wasted effort.

ULRICH DIRNAGL

\section{Train the PIs}

\section{Professor of neuroscience, Charité \\ University Medicine, Berlin.}

I teach statistics, experimental design and good scientific practice to $\mathrm{PhD}$ students and postdocs. They are all fascinated with

their scientific projects, and simply want to do 'the right thing' regarding the reproducibility, robustness and rigour.

Too often, my students tell me how steps to improve the validity of their work are obstructed by their supervisor or group leader. Quotes from their PIs include "I have published in Science and Nature"; "This will jeopardize our chances for acceptance"; or "This would take longer, and we might get scooped".

The importance of some techniques I teach, such as blinding, randomization and transparent analysis, are only now being emphasized in basic research. Methods for storing and analysing data have transformed in the past ten years. It makes no sense that senior researchers are exposed

"Let's

start with

mandatory

courses

in basic

statistics and

open science." to this only haphazardly, if at all.

Scientists have specialist training, but not a regulatory body or code of professional ethics. Nor do we have mandatory continuing professional devel-

opment - as do lawyers, vets, nurses and even football referees. Pilots keep their licence only if they document a certain number of hours in flight and undergo flight review. Physicians must participate in continuing medical education. Should we consider similar requirements for academic scientists?

Let's start with mandatory courses in basic statistics and open science for group and departmental leaders in biomedicine. They could attend the same course I teach. This would help a lot, even if it only empowers the trainees.

\section{MICHAEL J,ZIGMOND Show that you care}

Professor emeritus, Department of Neurology, University of Pittsburgh, Pennsylvania.

Since the 1980s, I have co-taught a course on 'survival skills' for lab members. I wish I could have also taught a companion course for lab heads: 'basic care of lab members'.

Such a course would hang on a simple dictum: show the members of your lab trainees and staff - that you care. Demonstrate in multiple ways that you consider yourself a mentor, and not just a supervisor.

That means providing clear guidelines on the relative roles that you and each trainee will have in selecting and executing research projects, on proper data management (including the maintenance of a lab notebook), on authorship, on support for attending meetings and on what it will take for you to feel that trainees are ready to move on.

I would also encourage you to start with a high level of supervision, then gradually allow more independence, checking back to make sure that all is going well and making it clear that you will be available whenever needed - even when travelling. Be sure to tell trainees to take an active role in their own training, including giving you feedback on how you might be more helpful.

Lab meetings are a time when you can establish your relationship with lab members, both as individuals and as a group. You can show that you value their ideas and consider your lab as an interactive community, not simply as a set of relationships between you and them.

Take time to celebrate successes - breakthroughs in the lab, presentations made, papers accepted. Praise in public, but keep strong criticism private and focused on specific actions or decisions, not on the individual.

And finally, the most important lesson I would teach? That the key to having a successful, productive lab - and to foster individuals who will go on to successful careers - is to make clear from the beginning that you are paying attention to lab members' welfare and their progress as scientists, not just to their specific projects and their contributions to your own ambitions.

\section{KATHERINE THOMPSON-PEER Get lab members multiple mentors}

\author{
Physiology postdoctoral scholar, \\ University of California, San \\ Francisco.
}

Anyone designing academic research from scratch would not create a system in which PIs have so much control over their lab members' research decisions and career opportunities. It bakes in too much fragility, with too few checks and balances to detect poor decisions and avoid bad situations. We must encourage trainees to seek out extra mentors.

Academia has been moving away from the model that a single mentor will be a $\mathrm{PhD}$ student's guru. Thesis advisory committees have been implemented because it is in the best interest of the student and the science to have multiple eyes and perspectives. Postdocs need that, too.

In my experience as a young postdoc, I 
knew that I should be seeking extra mentorship but never seemed to make time for it. It was only when I applied for a grant intended to help postdocs transition to independent positions that I began actually meeting with faculty members outside my own lab. Input from people besides my PI helped me to refine grant and job applications, and provided insight beyond either of our expertise.

Not everyone embraces the idea that it is essential for a postdoc to talk to faculty members other than their advisers about their science and career. Some advisers are possessive, and some trainees are worried about overstepping, imposing or causing offence. Advisers should set the tone. They should be checking in with their postdocs regularly, asking who they have met with, and offering introductions.

One mentor cannot meet all the needs of any trainee

"One mentor cannot meet all the needs of any trainee or junior colleague." or junior colleague. New trainees should feel they are joining the university and not just the lab. They should be expected to build a network of mentors as well as collaborators - people with varied strengths willing to look at how they are collecting and analysing their data and designing their path forward. Department heads should ensure that everyone is informed

\section{TRACYT.CHOW Be explicit about expectations}

\section{Postdoctoral fellow at the University of California, San Francisco.}

Shortly after I joined the lab for my PhD, the joint heads called a special meeting. I was apprehensive. From everything I knew about how labs worked, formal meetings were usually requested by trainees, not investigators. It turned out that the content of that meeting had nothing to do with the particular scientific questions that drew me into the lab - how the ends of chromosomes are maintained. But it had a major, and positive, effect on my work as a scientist.

In retrospect, some of the topics seem trivial: we went into minute details on various ways to organize results of multiple experiments conducted simultaneously, and how to document where to find raw files. This conversation demonstrated how seriously my advisers took the need to track experimental details and progress, and that they expected every experiment to clearly state the purpose, experimental conditions, results and conclusions, as well as plans for the next experiments.

Something else happened during that meeting, too. Trainees were encouraged to talk about their expectations for the mentors, and to share what was and wasn't working. This also built a stronger bond between lab mates, and made us more comfortable approaching each other for future conversations.

As researchers, our conversations with advisers dwell so much on specific scientific ideas, specialized techniques and data interpretation that we sometimes omit discussions about what makes a great paper in our field, or how to plan a project that can both meet specific goals and be open to serendipity. Without realizing it, we end up making our best guesses on how to do good science rather than making time to discuss it. I am grateful that one such discussion occurred as early in my career as it did. That formal meeting to set expectations increased my self-awareness of how I work as a scientist and boosted my scientific insight. It taught me how easy it is to assume that others think similarly to us which often is not the case - and reminds me how important it is to make assumptions explicit, for others and for ourselves.

Over time, I have found ways to ensure that these essential conversations happen. For example, my postdoctoral fellowship required me to have a statement of scientific and professional growth signed off by my adviser each year. I used this opportunity to share my expectations and a trajectory for my career development. Whenever I communicate with my adviser (in person, or through Skype or e-mail) about project updates, new data or experimental plans, I work to keep the conversation going two ways, and indicate what feedback I'm seeking. For instance, I list ideas for next steps, state what I think is most promising and ask what they think is feasible. In lab and committee meetings, I ask for input about expectations and timelines for the work to be presented at a conference or submitted for publication, and whether it would be appropriate to reach out to a possible collaborator. I also consider when my advisers are likely to be most approachable. For one, I might want to start a conversation during a short walk to a seminar. Some are more open to discussion over morning coffee; others in the afternoon.

That invaluable conversation I had so long ago came about through happenstance: two lab heads realized that their disparate working styles might cause confusion. But it taught me how important it is that advisers and trainees make sure they happen. Conversations about lab expectations should occur as a matter of course, not chance. 